\title{
Synthesis and Study of Catalysts of Cracking on the Basis of Heteropolyacids
}

\author{
ZH.KH.TASHMUKHAMBETOVA ${ }^{1}$, N.K. ZHAKIROVA ${ }^{1}$, L.R. SASSYKOVA ${ }^{1 \star}$, K.A. \\ KADIRBEKOV $^{2}$, Y.A. AUBAKIROV ${ }^{1}$, A.S. ZHUMAKANOVA ${ }^{3}$ and A.M. NALIBAYEVA ${ }^{3}$
}

${ }^{1}$ Al-Farabi Kazakh National University, 71, Al-Farabi Ave., 050040, Almaty, Kazakhstan. 2JSC "A.B.Bekturov Institute of Chemical Sciences", Valikhanov Street, 106, Almaty, Kazakhstan. ${ }^{3}$ D.V.Sokolsky Institute of Fuel, Catalysis \& Electrochemistry, 142, D.Kunaev str., 050010, Almaty, Kazakhstan. ${ }^{*}$ Corresponding author E-mail: larissa.rav@mail.ru

http://dx.doi.org/10.13005/ojc/330613

(Received: September 16, 2017; Accepted: October 02, 2017)

\section{ABSTRACT}

The work aim was the preparation of cracking catalysts on the base of the natural zeolite from the Shankanay field (Kazakhstan), modified with mineral acids, organic acids and heteropolyacids (HPA); the research of the catalysts by physicochemical methods of investigation. Accordingly to IR spectroscopic analysis during decationization and dealumination, the natural zeolite retains its crystalline structure. Presumably formation of a bond of HPA with zeolite proceeds at modifying the chosen zeolite by HPA. It was found from the EM data the high degrees of dispersion and distribution of particles of $\mathrm{PW}_{12}$-HPA on the surface of clinoptilolite. EM images of a thin layer of the catalyst on the base of $\mathrm{PW}_{12}$-HPA and zeolite activated by an acid, show spots with the various magnitudes and different shapes and contrasts. The experiments on EDAXspectrometer demonstrate that these spots have the same compositions that are identical to the $\mathrm{PW}_{12}-\mathrm{HPA}$.

Keywords: Catalysis, Heteropolyacids, Zeolite of the Shankanay field, Cracking.

\section{INTRODUCTION}

Heteropolyacids (HPA) are the compounds of a proton with a complex anion of inorganic polyoxometallates - molybdenum, tungsten, less frequently vanadium, etc. ${ }^{1-3}$. In the solid state, HPA are ionic crystals consisting of a large heteropolyanion, a cation, crystallization water, and sometimes additional molecules. When water is removed, an ultramicroporous structure with pores $\sim 1 \mathrm{~nm}$ in size is formed ${ }^{4-6}$. The unique physicochemical properties of HPA, which provide great potential for the preparation of catalysts with controlled acidity, dispersity of the modifier metal, increased thermal stability, have led to their use as modifiers of heterogeneous catalysts in catalysis ${ }^{7-12}$. The highest value for catalysis is HPA of 12 row. They contain heteropolyanions - the structures of the most common heteropolyanion Keggin $\mathrm{X}^{\mathrm{x}} \mathrm{M}_{12}{ }^{\mathrm{vi}} \mathrm{O}_{40}^{\mathrm{X}-8}$ or $\mathrm{X}^{\mathrm{x}} \mathrm{M}_{12-\mathrm{n}}{ }^{\mathrm{v}} \mathrm{O}_{40}{ }^{\mathrm{X}-\mathrm{n}-8}$, where $\mathrm{X}$ is a central atom ( $\left.\mathrm{Si}^{\mathrm{iv}}, \mathrm{P}^{\mathrm{v}}, \mathrm{As}^{\mathrm{vi}}\right), \chi$ is its oxidation degree, $\mathrm{M}$ is metal (molybdenum, tungsten or vanadium) ${ }^{13-16}$. HPA of tungsten row $\mathrm{PW}_{12}-\mathrm{HPA}\left(\mathrm{H}_{3} \mathrm{PW}_{12} \mathrm{O}_{40} \cdot 6 \mathrm{H}_{2} \mathrm{O}\right)$ or of molybdenum row $\mathrm{PMO}_{12}-\mathrm{HPA}\left(\mathrm{H}_{3} \mathrm{PMo}_{12} \mathrm{O}_{40} \bullet 6 \mathrm{H}_{2} \mathrm{O}\right)$ 
are well studied ${ }^{4-7,17-20}$. In the Keggin anion $\mathrm{H}_{3} \mathrm{PW}_{12} \mathrm{O}_{40}$, for example, the tungsten atom is located in the center of the oxygen octahedron. The phosphorus atom is surrounded by $12 \mathrm{WO}_{6}$ octahedra, forming $\mathrm{PO}_{4}$ tetrahedron. This structure is retained in concentrated solutions of HPA even after the loss of several oxygen atoms. For this reason, HPA has, like zeolites, a high adsorption capacity. For example, polar molecules such as water and alcohols easily penetrate the pores of the HPA and leave the volume of the catalyst, expanding and compressing the distances between the keggin anions, while nonpolar molecules (eg, hydrocarbons) do not give such an effect. This model allows to successfully explain the characteristic behavior of HPA, for example, high catalytic activity at low temperatures, the Keggin structure has a sufficiently high strength ${ }^{22}$. Acid-catalytic liquid-phase processes based on HPA catalysts were carried out on an industrial scale, for example, hydration of propylene, isobutylene, butenes, polymerization of tetrahydrofuran ${ }^{23-27}$. HPA are strong Bronsted acids and surpass the strength of many mineral acids. HPA have stronger acid sites than the zeolites $H X$, $\mathrm{HY}$ and amorphous aluminosilicates. The acidity of the solid acidity of HPA close to acidity of superacids. This determines the prospects of their use as acidic homogeneous and heterogeneous catalysts. HPA can be applied to the surface of such carriers as $\mathrm{SiO}_{2}, \mathrm{TiO}_{2}$. The main carriers $-\mathrm{Al}_{2} \mathrm{O}_{3}, \mathrm{MgO}$, - tend to decompose HPA. The practical use of HPA is mainly due to their use as catalysts for the oxidation of unsaturated hydrocarbons, olefin polymerization, epoxidation. Solid HPA, including applied, are used as catalysts in the alkylation of aromatic compounds, hydration of olefins and in other acid-type reactions. Heteropolycompounds of molybdenum find application as flame delayers ${ }^{28}$. An even wider area is their use in reactions where it is necessary to combine acid-base and oxidation-reduction properties of the catalyst ${ }^{29}$. It is known that the acid nature of the catalyst plays a fundamental role in the cracking of hydrocarbon feedstocks. However, the information on the use of HPA in cracking is not numerous, and the cracking properties of HPAmodified natural zeolites have not been practically investigated ${ }^{8,30,31}$.

The aim of the work is the synthesis of cracking catalysts based on the natural zeolite of the Shankanay deposit (Kazakhstan), modified with mineral acids, organic acids and HPA and the study of the qualitative and quantitative compositions of the working surface of the catalysts by physical and chemical methods of investigation.

\section{MATERIALS AND METHODS}

To prepare long-chain $\alpha$-olefins from paraffins, cracking catalysts based on the natural zeolite of the Shankanay deposit (Kazakhstan) were synthesized by modifying the natural zeolite with mineral acids, organic acids and HPA. Samples were also prepared on the basis of industrial $\alpha-\mathrm{Al}_{2} \mathrm{O}_{3}$ (bulk density $0.68 \mathrm{~g} / \mathrm{cm}^{3}$ ) modified by HPA. To remove various metals from the cation surface (mainly alkaline and alkaline earth), the zeolite was treated with mineral acids. Both natural zeolite (NZ), and previously decationated with hydrochloric acid samples of natural zeolite ( $\mathrm{H}-\mathrm{NZ})$ were subjected to treatment with complexons. So, by one-, two- and three-fold modification of the natural zeolite with $1.75 \mathrm{~N} \mathrm{HCl}$ were prepared samples of cracking catalysts: H-NZ-1, H-NZ-2 and H-NZ-3.

For the selective removal of $\mathrm{Fe}^{3+}$ iron ions, which facilitate the carburization process, zeolite was treated with organic acids. For this purpose, chelating agents such as sulfosalicylic acid and citric acid (10\%, 20\% concentration), ethylenediaminetetraacetic acid and its disodium salt of EDTA (Trilon B, aqueous 10\% strength solution) were used. All these listed compounds with iron ions form stable water-soluble complexonates.

Processing of zeolites with HPA was carried out for strengthening of force of the acid centers on which cracking reaction proceeds. For this purpose the new catalysts for the cracking of decationized natural zeolite and industrial aluminum oxide have been prepared, which have been modified by the heteropolyacids of the molybdenum and tungsten series: $\mathrm{PMo}_{12}-\mathrm{HPA} / \mathrm{H}-$ $\mathrm{NZ}, \mathrm{PMo}_{12}-\mathrm{HPA} / \mathrm{Al}_{2} \mathrm{O}_{3}, \mathrm{PW}_{12}-\mathrm{HPA} / \mathrm{H}-\mathrm{NZ}$ and $\mathrm{PW}_{12}-\mathrm{HPA} / \mathrm{Al}_{2} \mathrm{O}_{3}$. HPA were applied in an amount of $1.0 \%$ to $10 \%$ by impregnation on the surface of a decationized natural zeolite $(\mathrm{H}-\mathrm{NZ})$ by a known technique ${ }^{7,9,15,19}$. 


\section{RESULTS AND DISCUSSION}

The structure and phase composition of the catalysts synthesized on the basis of the natural zeolite of the Shankanay deposit (NZ-1), as well as industrial alumina, modified by the HPA of the molybdenum and tungsten series $\left(\mathrm{PW}_{12}-\mathrm{HPA} / \mathrm{H}-\mathrm{NZ}-\right.$ 1 and $\mathrm{PW}_{12}-\mathrm{HPA} / \mathrm{Al}_{2} \mathrm{O}_{3}$ (the content of the HPA was $1 \%, 3 \%, 5 \%$, and $10 \%), 10 \%$ of $\mathrm{PMO}_{12}-\mathrm{HPA} / \mathrm{H}-\mathrm{NZ}-$ 1 and $10 \%$ of $\mathrm{PMO}_{12}-\mathrm{HPA} / \mathrm{Al}_{2} \mathrm{O}_{3}$ ) were studied by IR spectroscopy and X-ray diffraction analysis.

\section{1, 2. Shows the IR spectra of:}

1) The initial molybdenum heteropolyacid $-\mathrm{PMo}_{12}-\mathrm{HPA}$,

2) The initial sample of the natural zeolite of the Shankanay deposit - the acid-activated $\mathrm{H}-\mathrm{NZ}-1$,

3) The modified by molybdenum HPA initial sample of natural zeolite activated by acid$\mathrm{Plo}_{12}$-HPA/H-NZ,

4) Modified by tungstic HPA initial sample of natural zeolite activated by acid- $\mathrm{PW}_{12}-\mathrm{HPA} /$ H-NZ.

The IR spectra (Fig. 1, 2) of the starting $\mathrm{PMO}_{12}-\mathrm{HPA}$ and $\mathrm{PW}_{12}-\mathrm{HPA}$ contain the following main absorption bands: 510; 594; 789; 867; 962; 1,$065 ; 1,400 ; 1,618 ; 2,850 ; 2,925 ; 3,210 ; 3,419 \mathrm{~cm}^{-1}$, which are typical for the compound of the composition $\mathrm{H}_{3} \mathrm{PMO}_{12} \mathrm{O}_{40^{\bullet}} 6 \mathrm{H}_{2} \mathrm{O}$ and $\mathrm{H}_{3} \mathrm{PW}_{12} \mathrm{O}_{40} \cdot$ $6 \mathrm{H}_{2} \mathrm{O}$, respectively (Fig. 1, a; Fig. 2, a). The results of the investigation of the samples of $\mathrm{H}-\mathrm{NZ}-1, \mathrm{PMo}_{12}{ }^{-}$ HPA/H-NZ-1, PW 12 -HPA/H-NZ-1 by IR spectroscopy and their comparative analysis show that their spectra contain characteristic absorption bands of the clinoptilolite type zeolite in the region of 465 ; $615 ; 780 ; 1,060 ; 1,635 ; 3,460 \mathrm{~cm}^{-1}$. In the IR spectra of the zeolite sample of the Shankanay field activated by acid, these absorption bands are very clearly manifested (Fig. 1, b, c; Fig. 2b, c); at decationization and dealumination, the natural zeolite retains its crystalline structure.

As can be seen from Figures 1, 2, the modification of the HPC of an acid-activated sample of zeolite of the Shankanay deposit is unambiguously manifested in the IR spectra of the resulting catalysts. For example, when $\mathrm{PMo}_{12}-\mathrm{HPA}$ is introduced into the zeolite composition on the IR spectra of the catalyst, some absorption bands characteristic of zeolites are shifted and new bands appear.

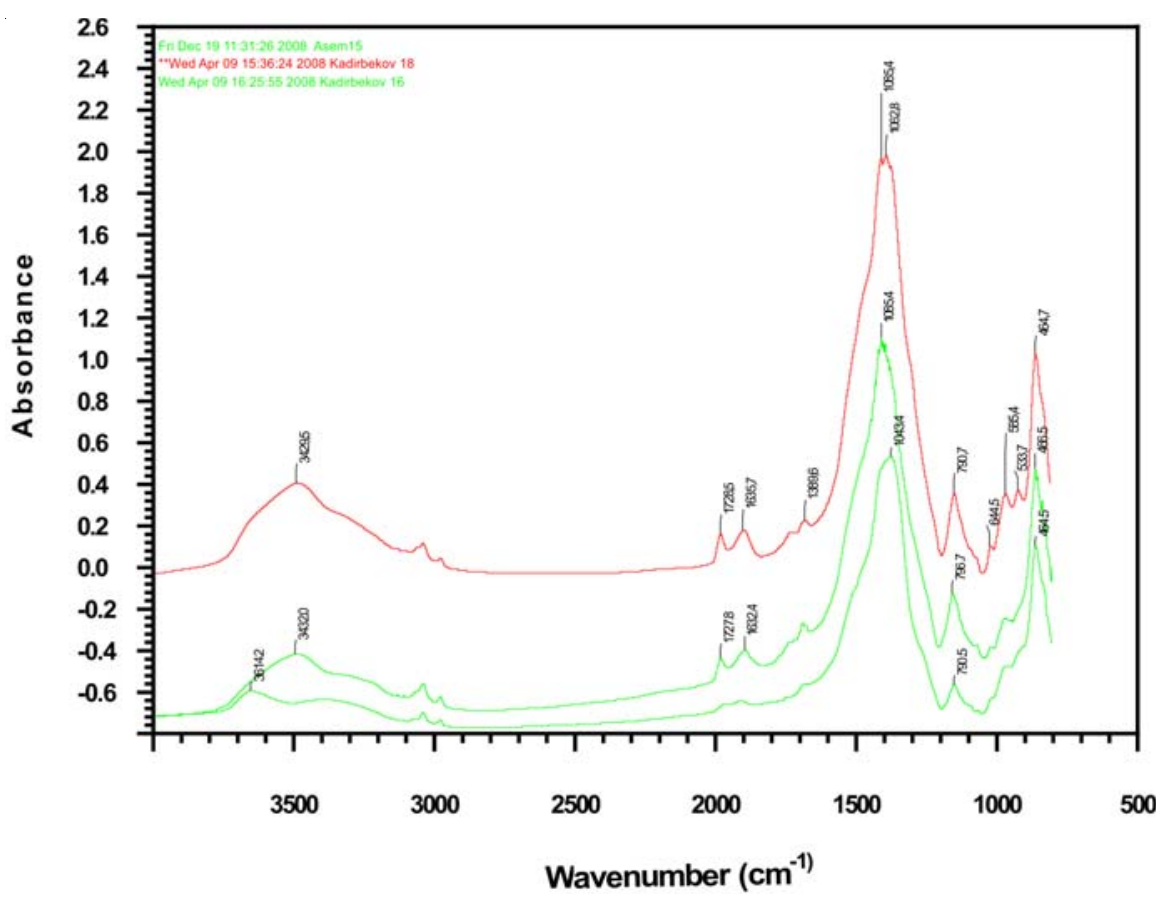

Fig. 1: IR spectra of the catalyst $10 \% \mathrm{PW}_{12}-\mathrm{HPA} / \mathrm{H}-\mathrm{NZ}-1$ and its components:

a) lower green curve- initial tungsten HPA - $\mathrm{PW}_{12}-\mathrm{HPA}\left(\mathrm{H}_{3} \mathrm{PW}_{12} \mathrm{O}_{40} \bullet 6 \mathrm{H}_{2} \mathrm{O}\right)$, b) upper green curve - H-NZ-1, c) red curve - the catalyst $10 \% \mathrm{PW}_{12}-\mathrm{HPA} / \mathrm{H}-\mathrm{NZ}-1$ 


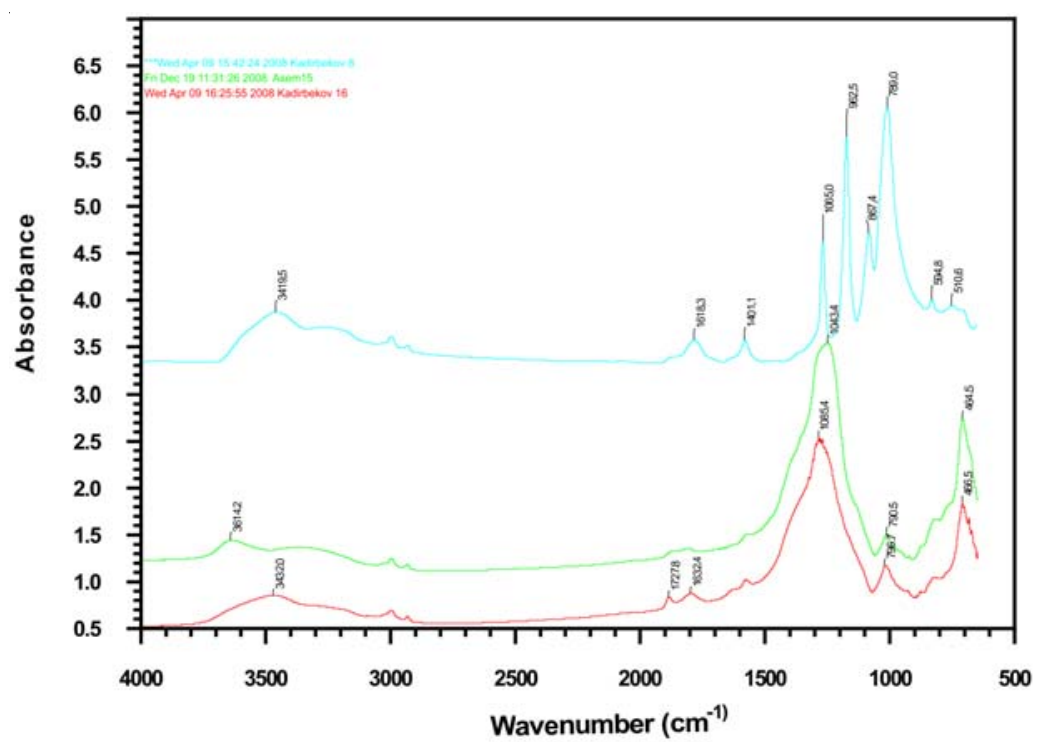

Fig.2. IR spectra of the catalyst $10 \% \mathrm{PMo}_{12}-\mathrm{HPA} / \mathrm{H}-\mathrm{NZ}-1$ and its components:

a) red curve- initial molybdenum HPA-Plo ${ }_{12}-\mathrm{HPA}\left(\mathrm{H}_{3} \mathrm{PMo}_{12} \mathrm{O}_{40} \bullet 6 \mathrm{H}_{2} \mathrm{O}\right)$,

b) green curve- $\mathrm{H}-\mathrm{NZ}-1$, c) blue curve - $10 \% \mathrm{PMo}_{12}-\mathrm{HPA} / \mathrm{H}-\mathrm{NZ}-1$ catalyst

Thus, a shift of the band in the region of $1,060 \mathrm{~cm}^{-1}$ to $1,097 \mathrm{~cm}^{-1}$ and $1,108 \mathrm{~cm}^{-1}$ is observed. The absorption band of $780 \mathrm{~cm}^{-1}$ disappears, and in the $800 \mathrm{~cm}^{-1}$ region a new band appears, which is typical for valence vibrations of the Si-O bond. This indicates the formation of a bond of HPA with a zeolite. Taking into account the appearance of a shift in the band in the range of 1,065 to $1,100 \mathrm{~cm}^{-1}$, it can be concluded that Al-O-Si-bonds are broken in the zeolite structure and Si-O-Si bonds are formed, and aluminum goes into the ion exchange position.

Dealumination of the clinoptilolite framework is also indicated by the appearance and growth of the intensity of the shoulder at $1,210 \mathrm{~cm}^{-1}$ on the IR spectra of this sample, referring to the asymmetric valence vibrations of the $\mathrm{Si}-\mathrm{O}$ end groups. However, complete destruction of the crystalline skeleton of the zeolite does not occur, only its partial amorphization is observed.

Figure 3 shows the EM-image and the elemental composition of the scanned section of the catalyst $\mathrm{PW}_{12}-\mathrm{HPA} / \mathrm{H}-\mathrm{NZ}-1$. The microanalysis data show that the content of its basic elements predominates on the surface of the zeolite, at the same time, the intensities of the spectra of the components of the HPA (tungsten and phosphorus) are clearly manifested. Apparently, this is due to the high degrees of dispersion and distribution of $\mathrm{PW}_{12}$-HPA particles over the surface of clinoptilolite.

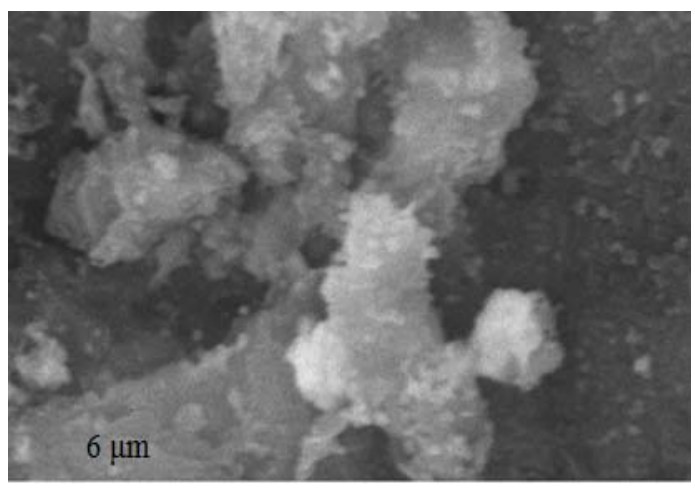

(a)

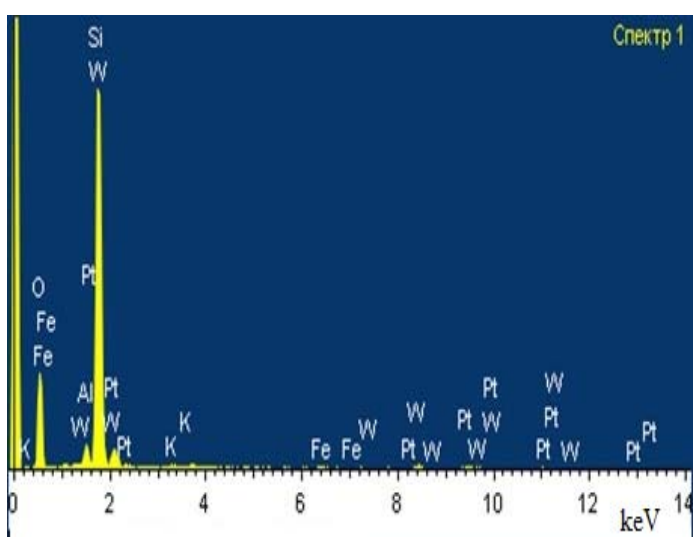

(b)

Fig.3: Electron microscopic image(a) and elemental composition (b) of the scanned section of the catalyst $\mathrm{PW}_{12}-\mathrm{HPA} / \mathrm{H}-\mathrm{NZ}-1$, obtained by SEM 


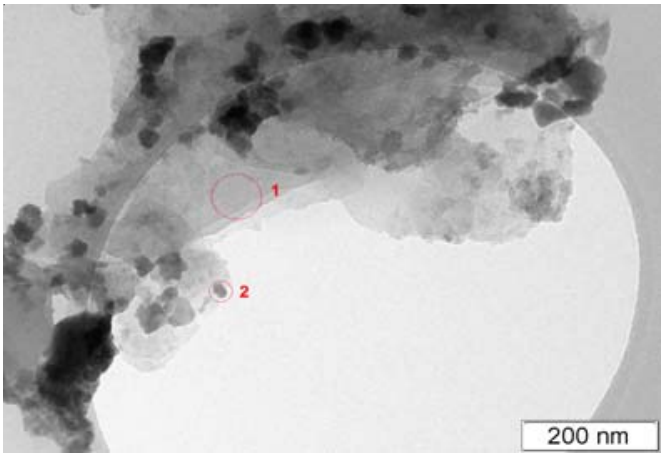

Fig.4. EM-image of the catalyst $\mathrm{PW}_{12}-\mathrm{HPA} / \mathrm{H}-\mathrm{NZ}-1$, obtained by the TEM-BP method.

Degree of resolution $1 \mathrm{~cm}=200 \mathrm{~nm}$
In electron microscopic images of a thin layer of catalyst $\mathrm{PW}_{12}-\mathrm{HPA} / \mathrm{H}-\mathrm{NZ}-1$, obtained by TEM (translucent electronic microscopy), it is possible to see spots of different sizes with different shapes and contrasts (Fig. 4). The microanalytical experiments on the EDAX-spectrometer showed that the above-mentioned spots have the similar compositions, identical to the PW $\mathrm{PW}_{12}$-HPA (Figure. 5).

It is considered ${ }^{12,21,25,30}$ that during the deposition and as a result of calcination of the catalyst, $\mathrm{PW}_{12}-\mathrm{HPA}$ is converted to a highly dispersed state, in which $\mathrm{PW}_{12}$-HPA particles exhibit special adsorption and catalytic properties.

D:\{EDAX32\}IMG|USRIVZ,GUESTS\}łkayraț081120łp_hpał43 1.s

Label A: 431

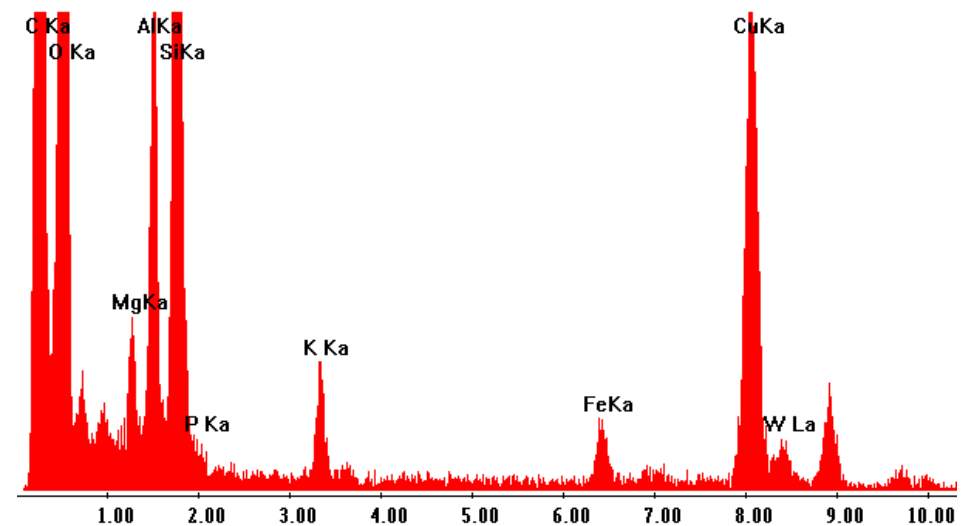

(a)

Label A: 432

D:\{EDAX32\}彳IMG\}USR|VZGGUESTS|kayratł081120\}p_hpał43 2.s

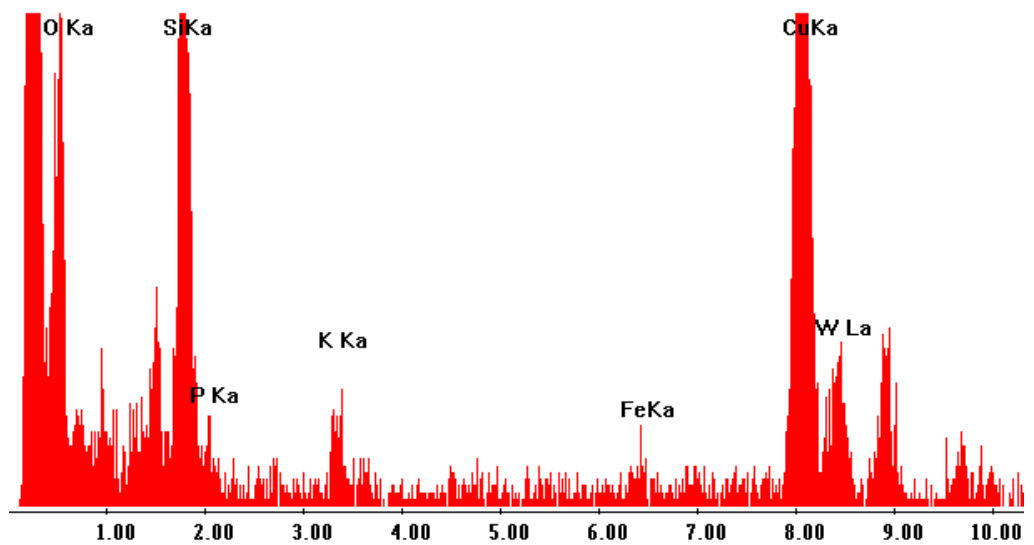

(b)

Fig.5. X-ray spectra of the catalyst surface $\mathrm{PW}_{12}-\mathrm{HPA} / \mathrm{H}-\mathrm{NZ}-1$ obtained on the EDAX-spectrometer: a) point No. 1 , b) point No. 2 
It is obvious that the emergence of nanostructures and the presence of a large number of strong acidic centers lead to an increase in the cracking activity of the catalyst of $10 \% \mathrm{PW}_{12}-\mathrm{HPA} /$ $\mathrm{H}-\mathrm{NZ}$ during the cracking of paraffins.

In the future, the authors of the article plan to continue research on the structure of catalysts based on HPA and zeolites, as well as testing of synthesized catalysts in cracking processes.

\section{CONCLUSION}

Cracking catalysts on the basis of natural zeolite of the Shankanay field (Kazakhstan) modified by mineral acids, organic acids and HPA and a research of qualitative and quantitative compositions of the working surface of catalysts by physical and chemical methods of a research were carried out. IR spectroscopic analysis shows that during decathionization and dealumination, the natural zeolite retains its crystalline structure. When modifying of the zeolite by HPA, it is possible to assume, with allowance for the analyzes carried out, the formation of a bond of HPA with a zeolite. Taking into account the shift of the band in the region of 1,065 to $1,100 \mathrm{~cm}^{-1}$, it can be concluded that the Al-O-Si- bonds are broken in the zeolite structure and $\mathrm{Si}-\mathrm{O}-\mathrm{Si}$ - bonds are formed, and the aluminum goes into the ion exchange position. Dealumination of the clinoptilolite framework is also indicated by the appearance and growth of the shoulder strength at $1,210 \mathrm{~cm}^{-1}$ on the IR spectra of this sample related to the asymmetric valence vibrations of the Si-O end groups. However, complete destruction of the crystalline skeleton of the zeolite does not occur, only partial amorphization is observed. X-ray patterns of the samples also indicate a change in the structure of the natural zeolite when its is modified by HPA. EM data show high degrees of dispersion and particle distribution of $\mathrm{PW}_{12}-\mathrm{HPA}$ on the surface of clinoptilolite.

\section{ACKNOWLEDGEMENTS}

We would like to express sincere gratitude to the Ministry of Science and Education of the Republic of Kazakhstan for grant financing (Project 2014-2017).

\section{REFERENCES}

1. Sutrisnoa, J.A. ECS Transactions 2010, 28 (27), 1-15.

2. Misono, M., Catalysis Rev.-Sci. Engng, 1978, 92, 269.

3. Beltramini, J.N. Studies in Surface Science and Catalysis, 2003, 146, 653-656.

4. Nomiya, K.; Murasaki, H.; Miwa, M., Polyhedron, 1986, 4, 1031-1033.

5. Kozhevnikov, I.V. Novoye v zhizni i tekhnike. Ser.khim., 1985, 12, 32.

6. Prabhahar, M.; Muralimanohar, R.; Sendilvelan, S. European Journal of Scientific Research, 2012, 73(4), 504-511.

7. Kulikov, S.M.; Timofeyeva, M.N.; Kozhevnikov, I.V. IzV. AN SSSR, ser. khim., 1989, 4,763-768.

8. Bykhovskii, M. Ya.; Shibanova, M. D.; Udalova, O. V.; Shashkin, D. P.; Korchak, V. N. Oil \& Gas Technologies, 2013, 1, 44-48.

9. Sassykova, L.; Gil'mundinov, Sh.; Nalibayeva, A.; Bogdanova, I. Revue Roumaine de
Chimie, 2017, 2, 107-114.

10. Sassykova, L.; Nalibayeva, A; Aubakirov, Y.; Tashmukhambetova, Zh.; Otzhan, U; Zhakirova, N.; Faizullaeva, M., Orient. J. Chem. 2017, 33(4), 1941-1948.

11. Kozhevnikov, I.V. Usp. Khimii., 1987, 9, 1417-1443.

12. Kozhevnikov, I.V. Usp. Khimii., 1982, 11, 1875-1896.

13. Pope, M. T. Progr. Inorg. Chem., 1991, 39, 181.

14. Khan, M.I.; Zudieta,J. Progr. Inorg. Chem., 1995, 43, 1.

15. Stranberg, R. Acta Chem. Scand, 1975, 29A(3), 359-364.

16. Dmitriyenko, S.G.; Goncharova, L.V.; Runov, V.K. Zhurn. fiz. Khimii, 1997, 12, 2227.

17. Matveyev, K.I.; Kozhevnikov, I.V. Kinetika $i$ kataliz, 1980, 5, 1189-1198.

18. Dubovik, D.B.; Ivanov, A.V.; Tikhomirova, T.I. Zhurn. analit. Khimii, 2003, 9, 902-921.

19. Kozhevnikov, I.V. Chem. Rev., 1998, 98, 171-198. 
20. Ono, Y., Ganday Gagaku, Chemistry Today, 1981, 124, 10-17.

21. Ghosh, A.K.; Moffat, J. J.Catalysis, 1986, 2, 238-245.

22. Kapustin, G.I.; Kustov, L.I.; Glonti, G.O Kinetika i kataliz, 1987, 5, 1129-1134.

23. Kapustin, G.I., Bruyeva, T.R., Klyachko, A.L. Kinetika i kataliz, 1990, 4, p.1017-1020.

24. Raj, C. S.; Arul, S.; Sendilvelan, S.; Saravanan, C. G. Energy Sources, Part ARecovery Utilization and Environmental Effects, 2010, 32(17), 1603-1613.

25. Wang, Y.; Wang, J. Petrochem. Technol, 2003, 6, 453-457.
26. Okuhara, T. Shokubai, Catalysts and Catalysis, 2003, 1, 32-34.

27. Ren, Y.; Yue, B.; Gu, M.; He, H. Materials, 2010, 3, 764-785.

28. Qi, Wen-bin; Zhu, Zi-Zhong, Talanta, 1986, 33(8), 694.

29. Baiseitov, D.A.; Tulepov, M.I.; Tursynbek, S.; Sassykova, L.R.; Nazhipkyzy, M.; Gabdrashova ,Sh.E.;Kazakov,Y.V.; Pustovalov, I.O.; Abdrakova, F.Y.; Mansurov, Z.A.; Dalton, A.B. Rasayan J. Chem. 2017, 10(2), 344 -348.

30. Noe-Spirlet, M.R.; Brown, G.M.; Busing, W.R.; Levy, H.A. Acta Cryst., 1975, 31A(3), 80.

31. Komaya,T.; Misono, M. Chemistry Letters, 1983, 12(8), 1177-1180. 